 \\ International Journal of Social Sciences and Management
}

\section{A Rapid Publishing Journal}

ISSN 2091-2986

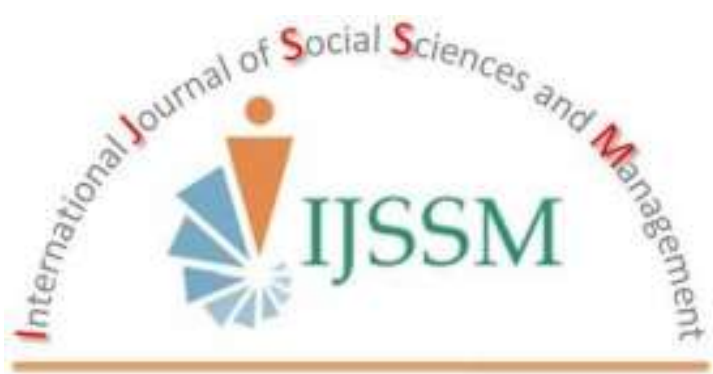

\section{Indexing and Abstracting}

CrossRef, Google Scholar, International Society of Universal Research in Sciences (EyeSource), Journal TOCs, New Jour, Scientific Indexing Services, InfoBase Index, Open Academic Journals Index (OAJI), Scholarsteer, Jour Informatics, Directory of Research Journals Indexing (DRJI), International Society for Research Activity (ISRA): Journal Impact Factor (JIF), Simon Fraser University Library, etc.

Vol- 3(2), April 2016 


\title{
Mini Review \\ SELECTING THE CORRECT MODEL FOR PROJECT EVALUATION: COMMENT ON IMPACT OF SUSTAINABLE SOIL MANAGEMENT PRACTICES ON HOUSEHOLD FOOD SECURITY IN RAMECHHAP DISTRICT, NEPAL
}

\author{
Krishna Prasad Pokharel \\ *Department of Agricultural Economics, Kansas State University, Manhattan, KS 66506, United States \\ *Corresponding author email: kpokharel@ksu.edu
}

\begin{abstract}
Conservation practices such as sustainable soil management (SSM) and no-tillage may increase production and productivity, which may help reduce food insecurity in household levels. Koirala et al. (2014) showed that the SSM practices have a high positive impact on food security and income in Ramechhap, Nepal. However, the impact of the SSM practices on food security and income were highly overestimated. Further, they did not explain how the impact of other factors on household food security and income are held constant to evaluate the impact of the SSM practices. This paper argues that the estimate of the impact of SSM practices on food security by Koirala et al. (2014) is highly upward biased due to the same unobserved factors affecting participation on the SSM practices and food security. This study shows an alternative method: an endogenous treatment effects model, which correctly estimates the impact of the SSM practices on food security. In addition, some issues that may affect food security and income measures associating with data collection are discussed.
\end{abstract}

Keywords: food security; sustainable soil conservation management; endogeneity

\section{Introduction}

Food security is one of the primary objectives of Millennium Development Goals (MDGs) (UNDP, 2005), which is a growing concern worldwide, particularly in developing countries like Nepal. The World Food Summit of 1996 defines food security as a situation "when all people at all times have access to sufficient, safe, and nutritious food to maintain a healthy and active life." This definition emphasizes on physical and economic access to food that meet people's dietary needs and their food preferences. The three pillars of food security are food availability, food access, and food utilization (FAO, 1996). Food availability refers to sufficient amount of food is available on a regular basis whereas food access refers to having sufficient resources to receive appropriate food for a nutritious diet. Similarly, utilization refers to the proper use of food for a healthy diet on accessed food. Utilization primarily focuses on dietary quality associated with inadequate intake of necessary vitamins and minerals for a healthy life (Barrett, 2010). Food insecurity affects food intake in quantity and quality, and eventually affects nutritional status and health of households (Mwaniki, 2006). ${ }^{1}$

\footnotetext{
${ }^{1}$ Note that adequate availability of food is necessary, but it does not ensure access to sufficient, safe, and nutritional food. For further explanation see Barrett (2010); UNDP (2005).
}

In Nepal, farmers practice subsistence agriculture with low soil productivity due to the lack of external inputs such as advanced seeds, chemical fertilizer or inappropriate use of these inputs and the development of the agricultural sector is impacted due to the lack of credit markets, poor physical infrastructure, lack of irrigation, and so forth. These factors affect the ability of subsistence farmers to have enough food, which increases the problem of food insecurity. Approximately $80 \%$ of the total population of Nepal involve in agriculture and the agriculture sector accounts for about 35\% of GDP in 2009/2010 (CBS, 2010). Moreover, malnutrition rates are among the highest in the world and approximately $25 \%$ people in 38 districts suffer from hunger (WFP, 2007). ${ }^{2}$

Many conservation practices such as sustainable soil conservation practices and agricultural intensification practices are implemented to decrease natural resource degradation, increase crop yields, and income (Dalton et al., 2014). The rural households in Nepal use the sustainable soil management (SSM) practices, which employ different technologies including, the use of farm yard manure and urine, legumes, and bio-pesticides.

Koirala et al. (2014) examined the impact of SSM practices on household food security in Ramechhap,

${ }^{2}$ Hunger is defined as the physical discomfort or weakness caused by the lack of food and can be measured at the individual level (WFP, 2007). 
Nepal. The authors found that SSM practices have positive impacts on food security, income, and so forth. To be specific, the results showed that the food sufficient month increased from 3.97 months to 7.67 months; an approximately $30 \%$ increase in food sufficiency from own production and income increased from Rs 25,758 to Rs 51,675 , which is a roughly $100 \%$ increase. The estimates for food sufficiency and income are highly overestimated. One of the reasons for high estimate could be the lack of consideration of the endogeneity (when the same factors affect outcome (food security) and participation in the SSM practices) problem they may occur on the project evaluation. Without accounting for endogeneity, the impact would be upward biased (Greene, 2002). The second reason could be biased responses for sensitive questions such as income. Similar explanation would work for the expenditure estimates as well.

The purpose of this study is to discuss statistical methods for examining the impact of a new project focusing on the conservation practices on food security and show that the approach of Koirala et al. (2014) grossly overestimated the impact of the SSM practices on food security and income levels of the participated households (treatment). This study is useful to farmers, policy makers, and researchers to understand the dimensions of food security particularly in developing countries.

\section{Conceptual Framework for Food Security}

Food security is a multidimensional issue related to individual, households, community etc. and many factors such as income, price of food items, and government support programs through which people obtain food may affect food security. In other words, food security is an outcome of livelihood strategies, which depends on available assets such human, social, and physical capitals to households (WFP, 2007). The main livelihood strategies for rural households in Nepal are livestock and crop productions. The conceptual framework for food security can be shown as in Fig. 1.

Measuring food security has been a big challenge for applied researchers due to its relation to a variety of factors. Researchers have used proxy methods for estimating the different aspects of food security such as coping strategies index, food expenditure index, dietary diversity measures (Maxwell, 1996; Barrett, 2010). Over the past five decades, the measure of food access accounts for most food insecurity. The food access method emphasizes on issues such as specific hunger and underweight data, which focuses on poverty reduction, food price, and social protection policies.

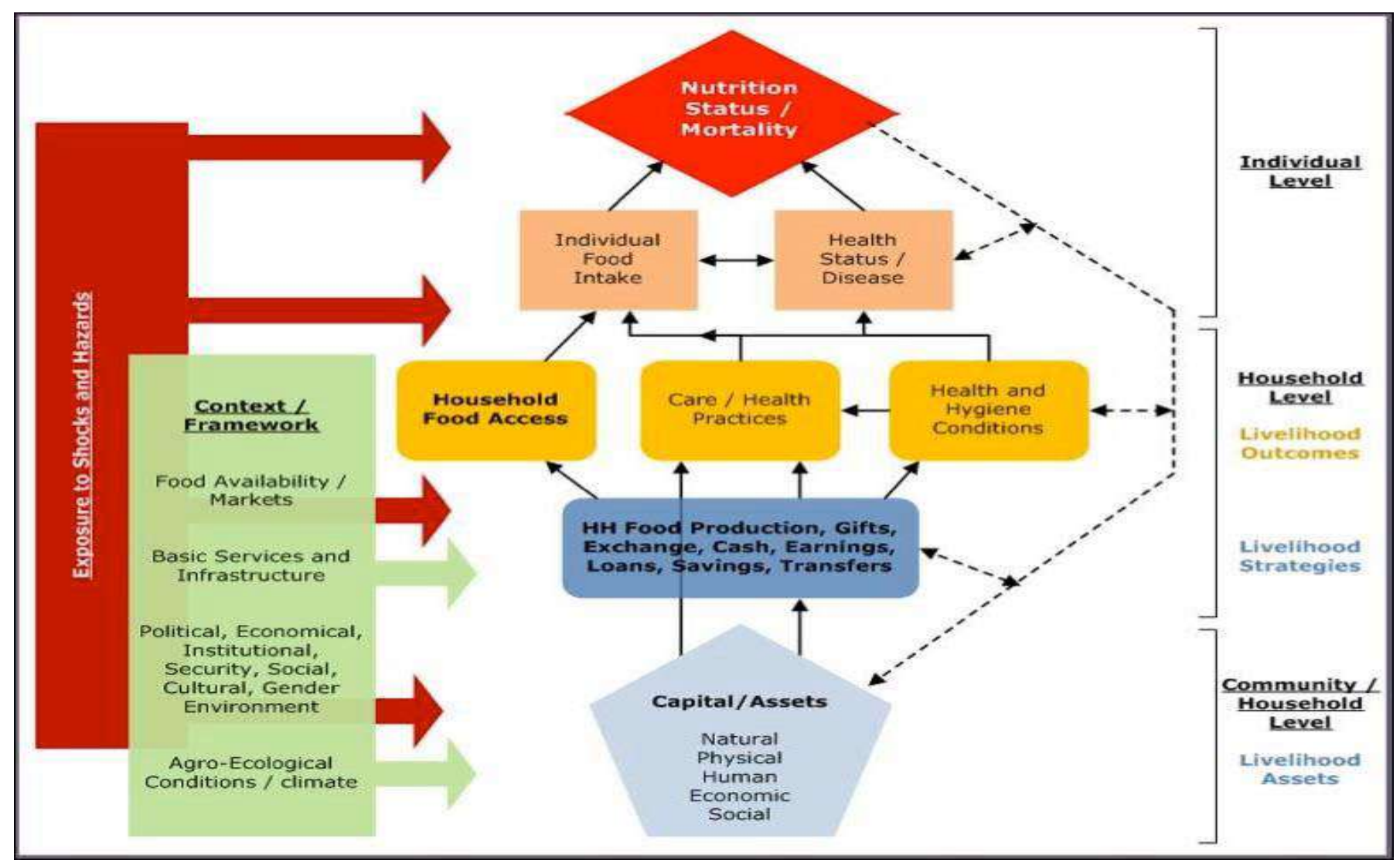

Fig. 1: Food and nutrition security conceptual framework

Source: Adopted from WFP (2012) 
Research has shown that different methods may give different estimates for food security. For example, the estimates for food insecurity obtained from individual or household data would be higher than the estimates obtained from aggregate level data due to the differences of distribution of nutrient and nutritional availability on intra- and inter households (Coates et al., 2007; Barrett, 2010). Similarly, other methods such as caloric adequacy to examine household food access is data intensive and difficult (Coates et al., 2007) and the use of the caloric adequacy method may be worse in developing countries due to a respondent's knowledge on particular concepts of food security.

Pyakuryal et al. (2010) estimated the impact of trade liberalization on food security in Nepal and found that per capital food availability was improved based on aggregated economic measures. Similarly, Yahaha and Pokharel (2015) evaluated the impact of sustainable agricultural intensification practices on food security in north-west Ghana using the household food insecurity access scale (HFIAS) indicator developed by the FANTA Project, USAID (Coates et al., 2007). The results showed that the HFIAS score is decreased roughly by $10 \%$ implying the participated households became relatively food secure after the implementation of sustainable agriculture practices.

Koirala et al. (2014) used paired t-test to examine the impact of the SSM practices on household food sufficiency. The results indicated that the food sufficiency increased from 3.97 months to 7.67 months; approximately a $30 \%$ increase in food sufficiency from own production. This is a highly overestimated impact of the SSM practices. Similarly, results indicated that income increased from Rs 25,758.33 to Rs 51,675, which is roughly a $100 \%$ increase in income. The impact of the SSM practices on income is also highly overestimated.

I argue that the authors did not properly account for other factors that affect income. Since the income is the product of price and quantity, in general, price has an upward trend. Instead of reporting a nominal value, the real monetary value could give a relatively real effect. The respondents might not have properly distinguished the income from different sources. In other words, farmers receive income from other sources except the crop production from the SSM practices land. For instance, the sources of income in rural areas of Nepal are the sales of agricultural products and livestock, wages, and remittances, which account for 30, 27, and 19\%, respectively in 2014, which significantly contributed to improving food security (MoAD, 2015). For instance, farmers keep a variety of livestock including cattle, yak, chaunri, buffalo, goats, sheep, poultry, and pigs in Ramechhap (CBS, 2013) and the sales of livestock could be the source of income. Moreover, since these are small farm holders (subsistence farmers), they may not able to sell their agricultural products so that it is hard to measure in monetary value, which may create hypothetical bias (Choi and Pak, 2005). Thus, it is important to separate the impact of other factors on measuring the change in income from a project. In addition, in Nepal, many adults have been going to other countries for employment and sending money to their family increasing the income of the participating households, which may increase family food security. These are important factors that should be accounted for when examining the impacts of the project implementation, itself on income and food security and an author should explicitly mention these possible factors.

Koirala et al. (2014) used the paired t-test to show the increase in income from SSM practices. However, there is no standard method that can directly link the SSM practices to income growth. Moreover, the test may incorrectly estimate when the same unobserved factors affect both participation and food security. This is a big challenge for economic or social research. Without accounting for endogeneity, the impact would have an upward bias. Koirala et al. (2014) also argued that the SSM practices affected food availability, accessibility, stability, and use.

The impact of the SSM practices on food availability and food accessibility probably can be measured by using perception questions. However, the concept of food use is not straightforward. The standard definition of food use (utilization) refers to dietary quality, focusing on deficiencies of essential nutrients or inadequate intake of essential minerals and vitamins. Perception data may not sufficiently measure food use problems including micronutrient deficiencies so that the lack of micronutrient cannot be known precisely (Barrett, 2010). A question I pose to the authors is how the measurement of food utilization in rural areas of Ramechhap taken, where roughly $34 \%$ people of total population and $43 \%$ female cannot read and write, respectively (CBS, 2013)? This situation creates more challenges in measuring food utilization.

The second reason of bias could be to survey design (not accounting for bias responses, which would give bias estimates). The responses may also be affected by wording, types of survey questionnaire, and ignorance of the respondent about the subject. Analysts should be aware of a self-reporting bias, responsiveness to sensitive questions. Specifically, in a self-reporting response bias, a respondent may be willing to suppress or give false information such that they may report they have high income and food sufficiency. A well-known problem in survey design is that respondents systematically alter responses in a direction they perceive to be desired by 
interviewers (Choi and Pak, 2005). In other words, an interviewee responds in a way that looks good to an investigator. For example, farmers who adopted SSM practices, they might think the investigator wants more positive impacts of the program on food security and income. These factors may also give upward biased results.

Does a biased estimate have impact? If the estimated result is used for policy analysis, inference, prediction etc., it assumed that the results are correctly estimated. If the estimated result is not reliable, then it has strong negative implications for policy analysis and prediction weakening the work of applied economists and social scientists (Tomek, 1993). Thus, it is important to note that analysts should inform readers about possible factors that may cause for biased (either upward or downward) results and should point out the limitation of the study.

A standard survey design helps to remove or decrease bias results on food security. Many methods are available to examine the severity of food security. For example, during the 1990s Africare developed Months of Adequate Household Food Provisioning (MAHFP) to identify the vulnerable groups and the guidance was revised in 2004 to standardize the methods to examine the impact of the funded program on outcome variables (Africare, 2005). Other methods are the Global Food Security Index (GFSI), the Poverty and Hunger Index (PHI) among others (Pangaribowo et al., 2013). Recently the USAID FANTA project developed the Household Food Insecurity Access Scale (HFIAS) indicator to estimate the prevalence of food insecurity annually in the United States and this indicator can be used to examine the impact of a project (e.g. the SSM practices) on outcome (household food insecurity) (Coates et al., 2007).

Before explaining in detail about the HFIAS indicator, I discuss how perceptions of household on nutritional requirements may also affect the response, especially in the hilly and mountainous regions of Nepal. For example, rice is a main cereal for meal such that households may perceive that the consumption of corn or oat decreases the quality though nutrition has been relatively remained constant, but it may change the response of the household (Coates et al., 2007). This is a very sensitive issue and usually happens in the western region of Nepal. Each year, there is a lack of food in the western regions of Nepal like Mugu, Dolpa, Humla and other neighboring districts. People from the region spend one to two days on the way to receive a small amount of rice from the offices of the Nepal Food Corporation (Nepal Khadya Sansthan). This indicates that researchers should design questionnaires to avoid perception biases.

The HFIAS indicator is relatively simple, but methodologically rigorous (Coates et al., 2007). The
HFIAS indicator has been widely used to survey participant households for examining the food insecurity (access) in both developed and developing countries. The HFIAS indicator includes behaviors and attribute domains that relate to various aspects of food insecurity. To examine the impact of a project (e.g. the SSM practices) on food security from the perspective of food access, the household food insecurity access scale (HFIAS) indicator can be used, which includes occurrence and frequency of occurrence questions. The HFIAS indicator is a scale measure spanning from 0 to 27. The scale of 0 indicates high food access and 27 refers low food access (Coates et al., 2007). After obtaining the HFIAS score, the endogenous treatment effects model can be used to examine the impact of a project (e.g. SSM practices) on an outcome variable (e.g. food access). The endogenous treatment effect model is widely used in measuring program effectiveness such as on the examination of college education on earnings (Greene, 2002). Angrist et al. (2001) provides detailed explanations on the treatment effect model.

\section{The Endogenous Treatment Effects Model}

This section briefly explains the endogenous treatmenteffects (ETE) model that can be used to examine the impact of a new project on outcome. The ETE model allows for correlation between unobserved factors affecting the household participation decisions and those affecting the household food insecurity access. ${ }^{3}$ The ETE model to examine the impact of household participation on food insecurity access scale measure (HFIAS) can be expressed as follows similar to (Greene, 2002):

HFIAS $_{\mathrm{i}}=\mathrm{X}_{\mathrm{i}}{ }^{\prime} \beta+\delta \operatorname{Part}_{\mathrm{i}}+\epsilon_{\mathrm{i}}$

Where, Part ${ }_{i}$ refers to participation, which is a binary variable (participate or do not participate on the SSM program). The coefficient of participation $(\delta)$ cannot capture the impact of participation on HFIAS $\mathrm{S}_{\mathrm{i}}$ because this is the case of whether household i participates in the SSM practices or not. This problem is known as the case of selfselection in statistics. If a researcher ignores the potential endogeneity of participation, it would highly overestimate the effect of participation on household food security access scale. The household participation decisions (treatment) are based on the household, individual and farm characteristics $W_{i}$, which can be written as:

$$
\begin{aligned}
& \operatorname{Part}_{\mathrm{i}}^{*}=\mathrm{W}_{\mathrm{i}}^{\prime} \lambda+\mathrm{u}_{\mathrm{i}} \\
& \operatorname{Part}_{\mathrm{i}}^{*}= \begin{cases}1 & \text { if Part } \\
0 & \text { Otherwise }\end{cases}
\end{aligned}
$$

\footnotetext{
${ }^{3}$ For the endogenous treatment effect model explanation, for convenience, I use the SSM practices as a new project for which the impact should be evaluated on household food access. Instead of HIFAS, other indictors can also be used in (Eqn. 1).
} 
Where $X_{i}$ and $W_{i}$ are covariates that are unrelated to the error terms. The assumption is that $\epsilon_{i}$ and $u_{i}$ are jointly normally distributed with mean zero and variance covariance matrix $\boldsymbol{\Sigma}$ given as:

$\boldsymbol{\Sigma}=\left(\begin{array}{cc}\sigma_{1}^{2} & \rho \sigma_{1} \\ \rho \sigma_{1} & 1\end{array}\right)$

The above model can be estimated using a two-step estimator as a participation decision model as in (Eqn. 2) and the outcome model as in (Eqn. 1). This model will provide consistent estimates of household participation decision on the food insecurity access accounting for the endogenous participation. The use of the dummy variable model as given by (Eqn. 2) for analyzing treatment effects and participation has been widely used in applied economics and social sciences. There are many variations of the model in estimating the project impacts including from the analysis of education (Willis and Rosen, 1979) and with different forms. Maddala (1993) provides a long list for the use of the model in different areas.

\section{Conclusion}

Food security is a growing concern in developing countries, especially in Nepal where the majority of population depends on subsistence agriculture. Different projects have been adopted to increase yield and income of subsistence farmers in rural areas of Nepal. For example, sustainable soil conservation practices, no-tillage have positive impacts on production and productivity. These kind of practices may increase food security of households as well. However, the findings from a very small size and short period of time weaken the generalization of the results. The sample size of Koirala et al. (2014) was 120 households and the results cannot be generalized to population and their method may not estimate the impact. Therefore, investigations with large sample and long periods are required to examine the impact of the sustainable soil conservation practices on food security in Nepal. In addition, questionnaire should be properly designed to avoid possible biases due to wording or sensitive issues such as age, income. In a social science study, researchers cannot control the factors as in a natural science experiment. Thus, extra caution should be taken to analyze data and interpret the results.

The proper use of statistical models with quality data may help to increase the quality and the reliability of a study. Even if researchers have high quality data, but if the data are not analyzed using proper statistical tools, it may provide the inaccurate estimates (Shrivastava, 2015). Moreover, the estimated result is used for different purposes (e.g. policy analysis, prediction, and inference), if the estimated result is not reliable, then it has strong negative implications for policy analysis, inference, prediction, which weaken the work of applied researchers (Tomek, 1993). Thus, the proper use of statistical tools with an appropriate sample size would be a minimum requirement for a social science empirical research even in developing countries.

\section{Acknowledgement}

This material is based upon work supported by National Science Foundation Grant: From Crops to Commuting: Integrating the Social, Technological, and Agricultural Aspects of Renewable and Sustainable Biorefining (ISTAR); NSF Award No.: DGE-0903701.

\section{References}

Africare (2005) How to measure the months of adequate household food provisioning (MAHFP) in food security interventions (FSI). Revised February. Unpublished internal guidance. Washington DC: Africare/Headquarters.

Angrist J (2001) Estimation of limited dependent variable models with dummy endogenous repressors simple strategies for empirical practice. Journal of Business and Economics Statistics 29: 2-15.

Barrett CB (2010) Measuring food insecurity. Science 327:825828.

CBS (2010) Statistical Pocket Book Nepal, Central Bureau of Statistics, National Planning Commission Secretariat, Thapathali, Kathmandu, Nepal.

CBS (2013) Statistical Year Book of Nepal, Central Bureau of Statistics, National Planning Commission Secretariat, Thapathali, Kathmandu, Nepal.

Choi BCK and Pak AWP (2005) A catalog of biases in questionnaires. Preventing chronic disease 2: 1-13. Available from: http://www.cdc.gov/pcd/issues/2005/jan/pdf/04_0050.pdf

Coates J, Swindale A and Bilinsky P (2007) Household food insecurity access scale (HFIAS) for measurement of food access: indicator guide. Washington DC: FANTA.

Dalton TJ, Yahaya I, and Naab J (2014) Perceptions and performance of conservation agriculture practices in northwestern Ghana. Agriculture, Ecosystems Environment 187: 65-71.

FAO (1996) Food and Agricultural Organization of the United Nations. World Food Summit. http://www.fao.org/wfs/

Greene WH (2002) Econometric Analysis, 5th Edition, ed. Englewood Cliffs, H.J Prentice.

Koirala B, Dutta JP, Dhakal SC, and Pant KK (2014) Impact of sustainable soil management practices on household food security in Ramechhap district, Nepal. Int. J. Soc. Sci. Mange. 1(4): 164-168.

Maddala G (1983) Limited dependent and qualitative variables in econometrics. New York: Cambridge University Press.

Maxwell S (1996) Food security: a post-modern perspective. Food policy 21:155- 170.

MoAD (2015) Nepal food security bulletin. 43: 1-6 www.moad.gov.np. 
Mwaniki A (2006) Achieving food security in Africa: Challenges and issues. UN Office of the Special Advisor on Africa (OSAA)

http://www.un.org/africa/osaa/reports/Achieving20Africa -Challengespp.

Pangaribowo EH, Gerber N, and Torero M (2013) Food and nutrition security indicators: a review. Working Paper 108, February 2013.

Pyakuryal B, Roy D, and Thapa YB (2010) Trade liberalization and food security in Nepal. Food Policy 35(1): 20-31.

Shrivastava UP (2015) Challenges in social science research. Int. J. of Soc. Sci. Manage. 2(1) -1-2.

Tomek WG (1993) Confirmation and replication in empirical econometrics: A step toward improved scholarship. American Journal of Agricultural Economics 75: 6-14.
UNDP (2005) United Nations Development Programmme (UNDP): Millennium Development Goals Report 2005, New York, NY.

WFP (2007) Comprehensive food security vulnerability analysis Nepal. https://www.wfp.org/countries/nepal

WFP (2012) Comprehensive food security vulnerability analysis Ghana.

http://www.humanitarianresponse.info/system/files/docu ments/ files/wfp257009_0.pdf.

Willis R and Rosen S (1979) Education and self-selection. Journal of Political Economy 87: S7-S36

Yahaha I and Pokharel KP (2015) The impact of sustainable agricultural intensification practices on household food access in North Western Ghana. Working Paper. Department of Agricultural Economics, Kansas State University, Manhattan, KS, USA. 